\title{
BMJ Open Non-accidental non-fatal poisonings attended by emergency ambulance crews: an observational study of data sources and epidemiology
}

\author{
Ann John, ${ }^{1}$ Chukwudi Okolie, ${ }^{1}$ Alison Porter, ${ }^{1}$ Chris Moore,${ }^{2}$ Gareth Thomas, ${ }^{1}$ \\ Richard Whitfield, ${ }^{2}$ Rossana Oretti, ${ }^{3}$ Helen Snooks ${ }^{1}$
}

To cite: John A, Okolie $C$ Porter $\mathrm{A}$, et al. Nonaccidental non-fatal poisonings attended by emergency ambulance crews: an observational study of data sources and epidemiology. BMJ Open 2016;6:e011049. doi:10.1136/bmjopen-2016011049

- Prepublication history and additional material is available. To view please visit the journal (http://dx.doi.org/ 10.1136/bmjopen-2016011049).

Received 5 January 2016 Revised 18 July 2016 Accepted 19 July 2016

CrossMark

\section{${ }^{1}$ Swansea University Medical School, Swansea, UK ${ }^{2}$ Welsh Ambulance Services NHS Trust, H.M.Stanley Hospital, St Asaph, Denbighshire, UK ${ }^{3}$ Community Addiction Unit, Cardiff and Vale University Health Board, Cardiff, UK}

Correspondence to Dr Ann John; a.john@swansea.ac.uk

\section{ABSTRACT \\ Background: Non-accidental non-fatal poisoning (NANFP) is associated with high risk of repeat episodes and fatality. This cross-sectional study aims to describe the data sources and epidemiology of non-fatal poisonings (NFPs) presenting to the emergency ambulance service. \\ Methods: We assessed incidents of NFP across Wales from electronic ambulance call centre records and paper records completed by attending ambulance crews, December 2007 to February 2008. We descriptively analysed data completed by attending crews.}

Results: 92331 calls were made to the ambulance call centre, of which $3923(4.2 \%)$ were coded as 'overdose' or 'poisoning'. During the same period, ambulance crews recorded 1827 attended NANFP incidents in those categories, of which 1287 (70.4\%) had been identified in the call centre. $76.1 \%(1356 /$ 1782) were aged $15-44$ years and $54.2 \%$ (991/1827) were female. $75.0 \%(1302 / 1753)$ of incidents occurred in areas from the lower 2 quintiles of deprivation in Wales. Substance taken was reported in $90 \%$ of cases $(n=1639)$. Multiple ingestion was common ( $n=886,54.1 \%)$. Psychotropic was the most frequently taken group of substances $(n=585,32.0 \%)$ and paracetamol $(n=484,26.5 \%)$ was the most frequently taken substance prehospital. Almost half of patients had taken alcohol alongside other substances $(\mathrm{n}=844,46.2 \%)$. Naloxone was the most frequently administered treatment $(n=137,7.5 \%)$. Only $142 / 1827(7.8 \%)$ patients were not transported to hospital, of whom 4 were recorded to have been given naloxone.

Conclusions: We report new data on the epidemiology of NFP across substance types at national level, highlighting deficiencies in information systems and high levels of multiple ingestion. In order to develop policy and practice for this patient group prehospital and further along the care pathway, information systems need to be developed to allow accurate routine monitoring of volume, presentation and outcomes.

\section{Strengths and limitations of this study}

- This is the first study to present a picture of ambulance service attendance to incidents of non-accidental non-fatal drug poisonings in the UK. Only preliminary studies have so far been published of prehospital non-fatal poisonings using ambulance call centre data, many of which are limited by age of participants or substance ingested.

- This study is whole population-based with an ambulance service covering all of Wales.

- This study relied on data from ambulance crews captured in the unstructured narrative section of the patient clinical records (PCR). This was not verified independently in this study. PCRs also had missing and unreadable data.

\section{BACKGROUND}

Non-fatal poisonings (NFPs) are a major global public health issue and a considerable economic burden. ${ }^{1}$ They is one of the commonest reasons for general hospital admission in the UK, with Wales alone having a total of 7415 hospital admissions for NFPs in 2009. ${ }^{2}$ Almost all of this care is unscheduled, that is, unplanned, urgent or emergency. NFP pose a challenge to health services capacity to plan, provide and deliver care. Many NFPs are non-accidental and may be selfharm (intentional self-poisoning or selfinjury irrespective of motivation or intent to die)-although there are challenges to identifying which NFP can be defined as selfharm. Self-harm brings an increased risk of repeat episodes ${ }^{1}$ and potentially of suicide. ${ }^{3}$ Physical health and life expectancy are also severely compromised compared with the general population in those who self-harm. ${ }^{4}$

Emergency ambulance services will often be the first point of contact with health services 
for someone who has experienced a NFP who seeks help or help is sought for them. Optimal prehospital care is set out in the National Institute for Health and Care Excellence (NICE) guidelines, ${ }^{5}$ supported by clinical standards produced by the Royal College of Psychiatrists for all health professionals ${ }^{6}$ and a set of clinical practice guidelines developed specifically for UK ambulance services by the Joint Royal Colleges Ambulance Liaison Committee (JRCALC). ${ }^{7}$ These recommend transport to hospital unless the patient refuses, and provide advice for ambulance crews on treating poisonings where appropriate, for example, through the use of naloxone, which counteracts the effects of opioids. Studies in Australia ${ }^{8}$ and Norway ${ }^{9}$ have highlighted the role of ambulance services in providing treatment on scene, in particular for opioid poisonings. The use of emetics and activated charcoal was not a prehospital option at the time of this study and are unlikely to become so because of the difficulty of administration and risk of aspiration. ${ }^{89}$

Ambulance service records have the potential to provide useful data to improve our understanding of the epidemiology of non-accidental non-fatal poisonings (NANFPs) and to help plan services. Only preliminary studies have so far been published in this field, ${ }^{10-12}$ and they are limited in terms of the age of participants (1144 years) or substance (opioid overdose with naloxone treatment). ${ }^{11-13}$ In the UK, the main source of data on ambulance service activity is information gathered at the call centre, which is based on data provided by emergency ambulance service callers, coded clinically using structured prioritisation algorithms, with management information about vehicle dispatch and response times. These systems provide data for performance management, policy development, implementation and monitoring, at national and local levels, although the accuracy of clinical data has been found to be low. ${ }^{13} 14$ In addition, crews collect data when they attend the patient, recording it either on a paper form or in an electronic record. No study has assessed the accuracy of data sources, that is, call centre data compared with data collected by attending ambulance crews when describing the epidemiology of NFP or more particularly NANFP.

While there is a relatively clear picture of the epidemiology of the nearly 3000 fatal poisonings which occur in England and Wales every year, ${ }^{15}$ there is little research evidence nationally or internationally concerning the epidemiology of NANFPs attended by emergency ambulance crews.

\section{AIM AND OBJECTIVES}

Aim

To describe the data sources and epidemiology of NANFPs attended by emergency ambulance.

\section{Objectives}

To describe:

1. Pre-hospital emergency information systems in relation to identification and management of NFPs and NANFPs;
2. Demographic and clinical presentation of NANFPs attended by emergency ambulance: substance(s) taken; level of consciousness of patient; whether the patient had also consumed alcohol; incidence of violence; elicited suicidal ideation; presence of police; prehospital treatment; call outcome.

\section{METHODS}

\section{Study design}

We carried out this observational study of emergency ambulance service calls and attendances in the whole of Wales between December 2007 and February 2008. The study was commissioned by the Welsh Government in response to concerns raised, during the routine national drug-related death inquiry into deaths from poisoning (South Wales Drug Related Deaths Review Group. Personal communication. 28 February 2008), about the lack of information relating to the volume and patterns of presentation of NFPs to emergency services. It was part of a wider programme of research on drugs and the ambulance service carried out by Swansea University for the Welsh Government.

Research Ethics Committee approval was not required as the project was categorised as service evaluation (confirmed by Local Research Ethics Service, 2009).

\section{Study setting}

The Welsh Ambulance Services National Health Service (NHS) Trust (WAST) provides emergency ambulance services to the country's population of $\sim 3$ million. ${ }^{16}$ WAST formally adopted the JRCALC guidelines on poisoning in adults in January 2008, and had previously worked to locally developed guidelines.

\section{Data sources and items}

Data related to emergency ambulance service calls were stored in two systems used by WAST. Data related to the call itself, as recorded by the call taker in the call centre, were held electronically and were available for analysis: call takers in the ambulance call centre followed a structured prioritisation algorithm (Advanced Medical Priority Dispatch System-AMPDS ${ }^{13}$ in order to allocate a clinical and urgency code to each call, and also recorded the response of the service to the call. The second data system consisted of paper forms (patient clinical records-PCRs) completed by attending crews at the incident. The PCRs included identifying data, demographics and clinical details of patient condition and any treatments provided. PCRs were mostly structured forms, with tick boxes for many data items related to clinical assessment and treatment. However, some items of interest to this study, such as, substance taken and suicidal ideation, were only recorded by crews in a free-text narrative section (see online supplementary file 1). The PCR forms were collated at ambulance stations and sent monthly to a central location for scanning and storage. Images were individually retrievable by searching by incident number, which was a common field with the emergency call centre data set. 
WAST's two parallel information systems were not electronically linked, so incidents and individuals cannot be tracked across the two systems in this way. However, when the incident is handed over to paramedics to attend the call handler will supply their assigned AMPDS code and this is recorded on the PCR. Since both systems use different condition categories and coding systems, at the outset of the study the research team had to define which codes were relevant to the study from each data set. We included calls coded in the ambulance call centre as 'overdose/poisoning' (AMPDS Code 23) but were unable to distinguish accidental and non-accidental overdose or poisoning in the AMPDS call taker system. We included PCRs with relevant clinical codes or treatment: 'substance abuse' (Code D002), 'overdose' (Code D003), 'naloxone administered' (Code NLX), excluding accidental poisoning or overdose (Code T047). We did not include incidents where alcohol was the only reported substance taken (Code D001).

For the purposes of further analysis, PCR data were taken as the 'gold standard', since these were recorded by the ambulance clinician attending the patient face-to-face. We extracted data recorded about: substances ingested; consciousness level of patient; whether the patient had also consumed alcohol; incidence of violence or suicidal ideation; presence of police; prehospital treatment; call outcome.

\section{Study population}

We gathered data on all incidents in Wales for which an emergency ambulance service call coded as being for 'overdose/poisoning' (AMPDS Code 23) was made in the period from 1 December 2007 to 29 February 2008, and those incidents attended by ambulance crews in the same period where records completed by crews indicated that the patient had experienced a NANFP.

\section{Data extraction and measures}

Call centre data were cleaned to ensure that multiple calls or responses per patient were matched and that hoax, cancelled or other abortive calls were excluded.

We coded information from the PCRs (both structured and free text) on demography, clinical presentation, treatment and outcomes and entered it to an Access 2007 database. We extracted postcodes for the location of each incident, and categorised these postcodes using the Welsh Index of Multiple Deprivation (WIMD $)^{17}$ and the Rural and Urban Area Classification (RUAC). ${ }^{18}$ WIMD is a lower super output area measure of deprivation based on eight domains including income, health and education and reported as quintiles/fifths of deprivation. RUAC categorises areas at output area level by density of population into 'urban', 'town and fringe' or 'village, hamlet and isolated dwellings'. Unstructured/free-text information relevant to the study, including details of the substance taken, aggressive behaviour and police presence was independently coded by three research team members (RO, AP, GT) using a coding frame developed for the study in collaboration with clinical members of the team (see online supplementary file 2-free-text coding frame), with validation by double coding of a sample of $10 \%$ of the entire data set.

\section{Data analysis}

Data from the AMPDS and PCRs were then exported for descriptive statistical analyses into SPSS V.16.

Analysis and reporting of data are in accordance with STROBE guidelines. ${ }^{19}$

This study was commissioned by the Welsh Government (CONTRACT 206/2003) but the funder played no role in its design, interpretation or the writing of the report.

\section{RESULTS}

\section{Comparison of call centre and PCR data}

Calls categorised on AMPDS at the call centre as overdose or poisoning made up $4.2 \%$ of emergency calls to the ambulance service in Wales during the study period (3923/92 331). During the same period, ambulance crews completed 1843 PCR forms categorised by their attending crew as 'substance abuse', 'overdose' or where naloxone was administered. Sixteen of these were duplicates and were excluded. In total, 1827 incidents attended were therefore included in the analysis (figure 1).

Only one-third of calls (1287/3923) coded as NFPs in the ambulance call centre were confirmed as NANFPs by attending crews (table 1 ). Conversely 540 cases classified by crews as NANFP had not been identified in the call centre as NFPs, but had been assigned other codes across a wide range of categories (table 2), the most frequent being unknown $(189,35.0 \%)$, unconscious/fainting $(73,13.5 \%)$, psychiatric behaviour $(71,13.1 \%)$ and breathing problems $(34,6.3 \%)$.

\section{Patterns of presentation of cases: analysis of NANFP PCRs Demographics}

In total, $54.2 \%(991 / 1827)$ of the patients attended were female. In 45 patients the age was not recorded. The mean age of all patients was 33.9 years (IQR 2239 years) with a range of $1-95$ years. The majority of patients $(76.1 \%$; 1356/1782) were within the 15-44 age range, 33.6\% (598/1782) were aged 15-24 years and $0.4 \%(8 / 1782)$ were recorded as aged $<4$ years.

Seventy-four $(4.1 \%)$ of the 1827 PCR records collected were excluded from the area-level analyses because either there was no valid incident postcode recorded $(n=68)$ or the incident took place outside Wales $(n=6)$. The vast majority of incidents occurred in areas in the two most deprived quintiles: $614 / 1753(35.0 \%)$ in the most deprived fifth, $688 / 1753(40.0 \%)$ in the second most deprived fifth. Only 126/1753 (8\%) of incidents occurred in areas in the two least deprived quintiles. Most incidents were attended in the more populated urban areas of Wales (settlements with a population over $10000 ; 1346 / 1753,76.8 \%$ ). 


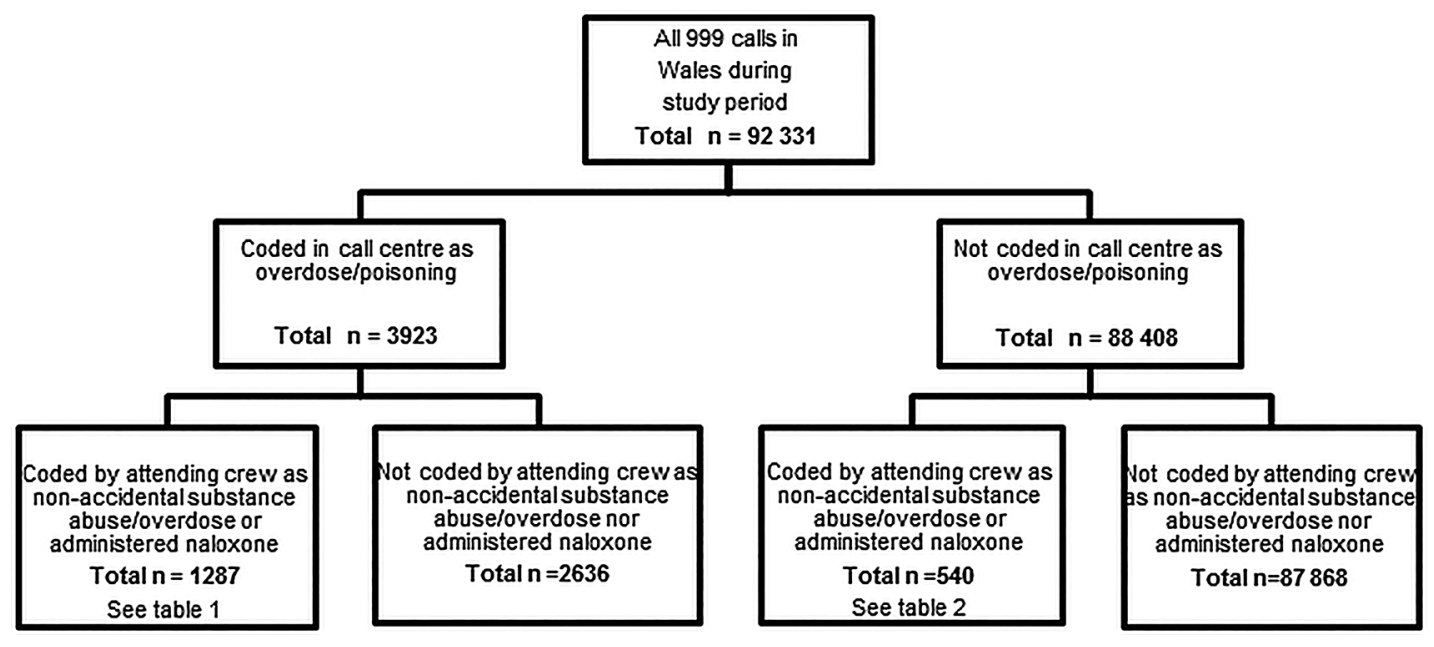

Figure 1 Calls categorised as non-fatal poisonings in the ambulance call centre and by ambulance crews on scene.

\section{Clinical/incident characteristics}

A wide range of substances were recorded on PCRs as having been taken by patients during the incident attended that were included in the study. Results are presented by substance taken with substances reported by group and name. Any one individual associated with an attended incident may appear more than once if more than one substance was ingested (table 3). Psychotropics were the most frequently reported group of substances, taken by $585 / 1827(32.0 \%)$ of patients. Paracetamol was the most frequently reported substance, taken by 484/ $1827(26.5 \%)$ of patients. In 188/1827 (10.3\%) of patients the substance or substances taken was either not known or not recorded. In the remaining 1639 patients, if alcohol is disregarded: $753(45.9 \%)$ ingested only one substance, $886(54.1 \%)$ ingested two or more. The most frequent combinations were: paracetamol and opioids $(137 / 1639,8.4 \%)$, paracetamol and non-steroidal antiinflammatory medication $(91 / 1639,5.6 \%)$, psychotropics and opioids $(86 / 1639,5.2 \%)$, paracetamol and psychotropics $(79 / 1639,4.8 \%)$. Alcohol had been taken alongside other substances by $844 / 1827 \quad(46.2 \%)$ patients in incidents attended.

Ambulance crews recorded Glasgow Coma Scale (GCS) scores for $1746 / 1827(95.6 \%)$ of the patients attended. The majority were fully conscious $(1416 / 1746$, $81.1 \%$ ), with a GCS of 15 . However, $\sim 5 \%$ were unconscious with GCS scores $\leq 8(83 / 1746)$. Most of those with scores of $\leq 8$ had GCS scores of 3 , that is, were categorised unresponsive when the ambulance arrived (63/ $1746,3.6 \%)$. This was mostly associated with substances taken with alcohol $(21 / 63,33.3 \%)$ and/or opioids (19/

Table 1 Number of overdose/poisoning codes assigned in the call centre and NANFP or treated with naloxone assigned on PCR forms

\begin{tabular}{|c|c|c|c|}
\hline $\begin{array}{l}\text { Call centre subcategory } \\
\text { code }\end{array}$ & Description & $\begin{array}{l}\text { Number of call } \\
\text { centre calls }\end{array}$ & $\begin{array}{l}\text { Number of NANFP attendances from } \\
\text { PCR (\% of NFP call centre codes) }\end{array}$ \\
\hline 23D01 & Unconscious & 477 & $158(33.1)$ \\
\hline 23D02 & Severe respiratory distress & 10 & $2(0.2)$ \\
\hline $23 \mathrm{C} 01$ & Violent & 497 & $200(40.2)$ \\
\hline $23 \mathrm{C} 02$ & Not alert & 675 & $176(26.1)$ \\
\hline $23 \mathrm{C} 03$ & Abnormal breathing & 299 & 69 (23.1) \\
\hline $23 \mathrm{CO4}$ & Antidepressants & 121 & $52(43.0)$ \\
\hline $23 \mathrm{C} 05$ & Cocaine or derivative & 7 & $5(71.4)$ \\
\hline $23 \mathrm{CO6}$ & Heroin & 26 & $6(23.1)$ \\
\hline $23 \mathrm{C} 07$ & Acid or alkali & 3 & $2(66.7)$ \\
\hline $23 \mathrm{C08}$ & Third party caller & 831 & $203(24.4)$ \\
\hline $23 \mathrm{C09}$ & Poison control & 7 & 0 \\
\hline 23B01 & $\begin{array}{l}\text { Overdose without priority } \\
\text { symptoms }\end{array}$ & 797 & 337 (42.3) \\
\hline 23001 & $\begin{array}{l}\text { Poisoning without priority } \\
\text { symptoms }\end{array}$ & 173 & $21(12.1)$ \\
\hline 23 other & & & 56 \\
\hline Total & & 3923 & 1287 \\
\hline
\end{tabular}


Table 2 Non-overdose codes assigned in the call centre to patients then coded by attending crews as non-accidental overdose/poisoning or treated with naloxone $(n=540)$

\begin{tabular}{|c|c|c|}
\hline $\begin{array}{l}\text { Call centre } \\
\text { code }\end{array}$ & Description & $\begin{array}{l}\text { Number of NANFP } \\
\text { calls from PCR data } \\
\text { (\% of all those } \\
\text { miscoded or not } \\
\text { labelled NFP at call) }\end{array}$ \\
\hline 01 & $\begin{array}{l}\text { Abdominal pain/ } \\
\text { problems }\end{array}$ & $4(0.7)$ \\
\hline 02 & Allergies & $2(0.4)$ \\
\hline 04 & $\begin{array}{l}\text { Assault/sexual } \\
\text { assault }\end{array}$ & $5(0.9)$ \\
\hline 05 & Back pain & $1(0.2)$ \\
\hline 06 & $\begin{array}{l}\text { Breathing } \\
\text { problems }\end{array}$ & $34(6.3)$ \\
\hline 09 & $\begin{array}{l}\text { Cardiac/ } \\
\text { respiratory arrest }\end{array}$ & $18(3.3)$ \\
\hline 10 & Chest pain & 18 (3.3) \\
\hline 12 & Convulsion/fitting & $28(5.2)$ \\
\hline 13 & $\begin{array}{l}\text { Diabetic } \\
\text { problems }\end{array}$ & $4(0.7)$ \\
\hline 17 & Falls & $15(2.8)$ \\
\hline 18 & Headache & $1(0.2)$ \\
\hline 19 & Heart problems & $4(0.7)$ \\
\hline 20 & Exposure & $1(0.2)$ \\
\hline 21 & $\begin{array}{l}\text { Haemorrhage/ } \\
\text { laceration }\end{array}$ & $10(1.9)$ \\
\hline 22 & $\begin{array}{l}\text { Industrial } \\
\text { accident }\end{array}$ & $10(1.9)$ \\
\hline 25 & $\begin{array}{l}\text { Psychiatric } \\
\text { behaviour }\end{array}$ & $71(13.1)$ \\
\hline 26 & Sick person & $21(3.9)$ \\
\hline 27 & Stab/gunshot & $5(0.9)$ \\
\hline 28 & Stroke & $3(0.6)$ \\
\hline 29 & Traffic accident & $1(0.2)$ \\
\hline 30 & $\begin{array}{l}\text { Traumatic } \\
\text { injuries }\end{array}$ & $3(0.6)$ \\
\hline 31 & $\begin{array}{l}\text { Unconscious/ } \\
\text { fainting }\end{array}$ & 73 (13.5) \\
\hline 32 & $\begin{array}{l}\text { Unknown } \\
\text { problem }\end{array}$ & $19(3.5)$ \\
\hline $\begin{array}{l}\text { Not known/ } \\
\text { not recorded }\end{array}$ & & 189 (35.0) \\
\hline Total & & $540(100)$ \\
\hline
\end{tabular}

63, 30.2\%). Medication was recorded as being administered by crews to $137 / 1827(7.5 \%)$ patients. Naloxone was administered to $102(5.6 \%)$ of these individuals, with more than one dose being administered on more than half of these occasions $(69 / 102)$. Other medication administered by ambulance crews included metoclopramide, furosemide, glucagon, atropine, diazepam and epinephrine. Fluids were recorded as being administered to $17 / 1827$ individuals $(0.9 \%)$.

Suicidal ideation was recorded in only $175 / 1827$ $(9.6 \%)$ of incidents attended. Aggressive or violent behaviour was recorded in an even smaller number of attendances $(52 / 1827,2.8 \%)$. The police were recorded as present in $9.6 \%(175 / 1827)$ of attendances, and alcohol combined with at least one substance was associated with half of these $(84 / 175,48.0 \%)$.

Only $142 / 1827(7.8 \%)$ patients in the incidents attended were not transported to hospital, of which almost half (71) were recorded as having refused transport. The largest number of patients not conveyed to hospital had taken opioids $(32 / 429,7.5 \%)$, of whom 4 were recorded to have been given naloxone. However, the highest rates of non-conveyance were found in incidents where the substance ingested was either not known (14/141, 9.9\%) or not stated (11/47, 23.4\%).

The highest demand for emergency ambulance services for poisonings was during 'out-of-hours' times. Out of 1182 incidents recorded on PCRs as NFPs, which recorded both a time and a date, $797(67.4 \%)$ had been attended either between 18:30 and 8:00, at the weekend, or on a bank holiday. Of the 1821 PCRs where a date was recorded, $615(33.8 \%)$ took place at the weekend, with Saturdays having the highest number of contacts with the ambulance service relating to NFPs (334, $18.3 \%)$.

\section{DISCUSSION}

\section{Key findings}

This is the first study to present a picture of ambulance service attendance to incidents of NANFP in the UK. We found the electronic data captured by ambulance service call centre AMPDS is not a reliable indicator of the incidence of NFP. This has implications for service planning for emergency care. The AMPDS was not designed as diagnostic tool, but as a way to rapidly identify and prioritise calls about life-threatening conditions. ${ }^{13}$ The information received by the call taker may well be incomplete. It is therefore unsurprising that ambulance call centre data record substantially higher numbers of NFPs than those identified on scene by attending ambulance crews. Conversely nearly one-third of those NFPs identified at scene are not those identified at the time the call is made. The quality of data recorded on PCRs was variable. Structured clinical assessment and treatment data were completed fully, but unstructured free-text data were of variable quality and completeness.

\section{Strengths and limitations of the study}

In this study, we report NFPs for which an emergency call was made. We do not know the proportion of all NFPs that this represents. People do not always present to emergency services, and routine recording of attendance at emergency department (ED) at the time of this study was unreliable and incomplete. Hence, the proportion of all NFPs is difficult to determine. A strength of this study is that it is whole population-based with an ambulance service covering the nation of Wales. 
Table 3 Characteristics of incidents of non-accidental non-fatal poisoning, by substance(s) ingested

\begin{tabular}{|c|c|c|c|c|c|c|c|c|c|c|c|}
\hline Substance & $\begin{array}{l}\text { Number of } \\
\text { people who } \\
\text { had taken } \\
\text { substance } \\
\mathrm{N}(\%)\end{array}$ & $\begin{array}{l}\text { Female } \\
\mathbf{N}(\%)\end{array}$ & $\begin{array}{l}\text { Age } \\
\text { Mean }\end{array}$ & $\begin{array}{l}\text { Reduced } \\
\text { consciousness } \\
(G C S \leq 8) \\
N(\%) \\
\end{array}$ & $\begin{array}{l}\text { Alcohol } \\
\mathbf{N}(\%)\end{array}$ & $\begin{array}{l}\text { Aggression } \\
\text { or violence } \\
\mathrm{N}(\%)\end{array}$ & $\begin{array}{l}\text { Suicidal } \\
\text { ideation } \\
\mathbf{N}(\%) \\
\end{array}$ & $\begin{array}{l}\text { Police } \\
\text { present } \\
\text { N (\%) }\end{array}$ & $\begin{array}{l}\text { Refused } \\
\text { treatment } \\
\mathrm{N}(\%) \\
\end{array}$ & $\begin{array}{l}\text { Refused } \\
\text { transport } \\
\mathrm{N}(\%) \\
\end{array}$ & $\begin{array}{l}\text { Taken to } \\
\text { hospital } \\
\mathrm{N}(\%) \\
\end{array}$ \\
\hline Any & 1827 (100.0) & $991(54.2)$ & 33.85 & $83(4.5)$ & $844(46.2)$ & $52(2.9)$ & $147(8.1)$ & $175(9.6)$ & $20(1.1)$ & $71(3.9)$ & 1685 (92.2) \\
\hline Psychotropics & 585 (32.0) & $322(55.0)$ & 33.56 & $22(3.8)$ & $316(54.0)$ & $22(3.8)$ & $62(10.6)$ & $59(10.1)$ & $6(1.0)$ & $22(3.8)$ & 559 (95.6) \\
\hline Antidepressants & $322(17.6)$ & $177(55.0)$ & 33.55 & $12(3.7)$ & $164(50.9)$ & $15(4.7)$ & $40(12.4)$ & $37(11.5)$ & $2(0.6)$ & $10(3.1)$ & 307 (95.3) \\
\hline Benzodiazepines & 279 (15.3) & $157(56.3)$ & 33.77 & $12(4.8)$ & $162(58.1)$ & $10(3.6)$ & $30(10.8)$ & $31(11.1)$ & $4(1.4)$ & $10(3.6)$ & 267 (95.7) \\
\hline Antipsychotics & $65(3.6)$ & $37(56.9)$ & 33.41 & $3(4.6)$ & $24(36.9)$ & $3(4.6)$ & $2(3.1)$ & $7(10.8)$ & $2(3.1)$ & $5(7.7)$ & $62(95.4)$ \\
\hline Paracetamol & $484(26.5)$ & 253 (52.3) & 34.85 & $29(6.0)$ & 219 (45.3) & 19 (3.9) & $30(6.2)$ & 47 (9.7) & $7(1.5)$ & $24(5.0)$ & 463 (95.7) \\
\hline Opiates & $429(23.5)$ & $240(56.0)$ & 33.28 & $24(5.6)$ & $181(42.2)$ & $24(5.6)$ & $42(9.8)$ & $38(8.9)$ & $5(1.2)$ & $16(3.7)$ & 397 (92.5) \\
\hline Codeine & 266 (14.6) & $149(56.0)$ & 34.65 & $16(6.0)$ & $134(50.4)$ & $15(5.6)$ & $36(13.5)$ & $25(9.4)$ & $4(1.5)$ & 7 (2.6) & $253(95.1)$ \\
\hline Diamorphine & $101(5.5)$ & $59(58.4)$ & 30.64 & $5(5.0)$ & $25(24.8)$ & $2(2.0)$ & $3(3.0)$ & $6(5.9)$ & $0(0.0)$ & $2(2.0)$ & $88(87.1)$ \\
\hline Buprenorphine & 57 (3.1) & 30 (52.6) & 32.62 & $2(3.5)$ & $20(35.1)$ & $0(0.0)$ & $3(5.3)$ & $4(7.0)$ & $1(1.8)$ & 7 (12.3) & 53 (93.0) \\
\hline Methadone & $14(0.8)$ & $9(64.3)$ & 26.50 & $2(14.3)$ & $6(42.9)$ & $0(0.0)$ & $1(7.1)$ & $2(14.3)$ & $0(0.0)$ & $1(7.1)$ & $10(71.4)$ \\
\hline Morphine & $12(0.7)$ & 7 (58.3) & 32.50 & $0(0.0)$ & 4 (33.3) & $0(0.0)$ & $0(0.0)$ & $1(8.3)$ & $0(0.0)$ & $0(0.0)$ & $12(100.0)$ \\
\hline NSAIDs & $223(12.2)$ & 118 (52.9) & 35.15 & 8 (3.6) & $112(50.2)$ & 8 (3.6) & 29 (13.0) & $20(9.0)$ & $2(0.9)$ & $6(2.7)$ & 209 (93.7) \\
\hline Ibuprofen & $154(8.4)$ & 85 (55.2) & 36.28 & $4(2.6)$ & 83 (53.9) & $4(2.6)$ & 21 (13.6) & $13(8.4)$ & $1(0.7)$ & 6 (3.9) & 144 (93.5) \\
\hline Aspirin & 47 (2.6) & $21(44.7)$ & 33.68 & $2(4.3)$ & 17 (36.2) & $0(0.0)$ & $6(12.8)$ & $4(8.5)$ & $0(0.0)$ & $0(0.0)$ & 44 (93.6) \\
\hline Diclofenac & $38(2.1)$ & 20 (52.6) & 34.34 & $2(5.3)$ & 20 (52.6) & $4(10.5)$ & $3(7.9)$ & $6(15.8)$ & $1(2.6)$ & $0(0.0)$ & 36 (94.7) \\
\hline Other known & 226 (12.4) & $130(57.5)$ & 35.00 & $10(4.4)$ & $100(44.3)$ & $10(4.4)$ & $7(3.1)$ & $25(11.1)$ & $2(0.9)$ & $13(5.8)$ & 208 (92.0) \\
\hline Cocaine & $60(3.3)$ & 29 (48.3) & 31.81 & $4(6.7)$ & 35 (58.3) & $3(5.0)$ & $0(0.0)$ & $6(10.0)$ & $1(1.7)$ & $3(5.0)$ & $54(90.0)$ \\
\hline Amphetamine & $36(2.0)$ & $20(55.6)$ & 37.23 & $0(0.0)$ & $15(41.7)$ & $1(2.8)$ & $2(5.6)$ & $5(13.9)$ & $0(0.0)$ & $1(2.8)$ & 35 (97.2) \\
\hline Cannabis & $36(2.0)$ & $20(55.6)$ & 35.21 & $1(2.8)$ & $17(47.2)$ & $3(8.3)$ & $1(2.8)$ & $4(11.1)$ & $1(2.8)$ & $0(0.0)$ & $31(86.1)$ \\
\hline Ecstasy & 34 (1.9) & $17(50.0)$ & 33.68 & $1(2.9)$ & $22(64.7)$ & $1(2.9)$ & $0(0.0)$ & $5(14.7)$ & $0(0.0)$ & $1(2.9)$ & 31 (91.2) \\
\hline Anticonvulsants & $32(1.8)$ & $18(56.3)$ & 37.76 & $2(6.3)$ & 7 (21.9) & $0(0.0)$ & $3(9.4)$ & $2(6.3)$ & $0(0.0)$ & $0(0.0)$ & $30(93.8)$ \\
\hline Cardiovascular & $23(1.3)$ & $10(43.5)$ & 33.05 & $3(13.0)$ & $8(34.8)$ & $0(0.0)$ & $1(4.4)$ & $2(8.7)$ & $0(0.0)$ & $0(0.0)$ & $23(100.0)$ \\
\hline Antimicrobials & $16(0.9)$ & $16(100.0)$ & 37.53 & $0(0.0)$ & $4(25.0)$ & $0(0.0)$ & $0(0.0)$ & $3(18.8)$ & $0(0.0)$ & 5 (31.3) & $15(93.8)$ \\
\hline Indigestibles & $11(0.6)$ & $10(90.9)$ & 40.36 & $0(0.0)$ & $5(45.5)$ & $0(0.0)$ & $0(0.0)$ & $0(0.0)$ & $0(0.0)$ & $5(45.5)$ & $10(90.9)$ \\
\hline Not known & $141(7.7)$ & $68(48.2)$ & 34.45 & $6(4.3)$ & $14(9.9)$ & $4(2.8)$ & $8(5.7)$ & $12(8.5)$ & $0(0.0)$ & $5(3.6)$ & $126(89.4)$ \\
\hline Not stated & $47(2.6)$ & $32(68.1)$ & 34.22 & $0(0.0)$ & $0(0.0)$ & $0(0.0)$ & $2(4.3)$ & $6(12.8)$ & $1(2.1)$ & $3(6.4)$ & $36(76.6)$ \\
\hline
\end{tabular}

Note: multiple ingestion was common; therefore, the sum for ingestion of individual substances does not add up to the collective total of the group to which the substance ingested belongs.

GCS, Glasgow Coma Scale; NSAIDs, non-steroidal anti-inflammatory drugs. 
However, we were unable to track incidents and individuals across the two information systems (call centre and PCR) because they are not electronically linked. Assigned call centre codes are recorded on PCRs when the call handler contacts the ambulance crew to handover the incident.

This study relied on data recorded by ambulance crews concerning substances taken, captured in the unstructured narrative section of the PCR. This was not verified independently in this study. We reported attended incidents across the study period not individuals, since this was not facilitated by the paper-based format. PCRs also had missing and unreadable data. As previous studies both in the UK and internationally have shown, ${ }^{9}$ ambulance service records are frequently incomplete, making it hard to get a complete picture of the clinical presentation of patients, their demography or patterns of care provision. Thus, reliance on manual sorting of cases by ambulance service staff may have introduced some inaccuracy into findings. Unlike previous studies of NFPs in the setting of a hospital ED, ${ }^{20} 21$ the research team did not have access to reliable, searchable electronic data. In those ambulance services which have moved from paper PCRs to electronic reporting systems, processes of data retrieval and management are likely to be far more straightforward than in the Welsh Ambulance Services Trust, although the impact of this on completeness of data has yet to be assessed.

\section{Comparison with previous studies}

Most current literature in this field relates to ED attendance and hospital admission and the distribution of substances ingested and the association with alcohol found in this study is consistent with these studies. ${ }^{6} \begin{array}{ll}7 & 922\end{array}$ Previous studies have also shown that most self-harm ED attendances occur out-of-hours between 17:00 and 9:00 when those who self-harm are less likely to receive a psychosocial assessment than those attending between 9:00 and 17:00 with many leaving before being seen by any clinical staff. ${ }^{23}$ Psychosocial assessments of needs are recommended by $\mathrm{NICE}^{8}$ and associated with reduced repetition. However, those at greatest risk of repetition are least likely to receive these assessments. ${ }^{22}$

In Wales, the majority of patients attended with NANFP were transported to hospital. This is a very different picture from, for example, Norway where one study found that $40 \%$ of people who were attended for NFP, the majority of whom were poisoned with opioids, were left at scene after treatment. ${ }^{9}$ This contrasts with only $7.8 \%$ in our study, and may reflect different working practices across countries or higher conveyance rates in those where poisoning is non-accidental.

In keeping with other studies, ${ }^{92}$ this study found that NFPs are experienced by both genders, predominately aged 15-44 years and taking psychotropic medication, paracetamol or opioids. One smaller study of 585 patients assessed ambulance crew data only and found being male and ingesting opioids were important predictors of adverse clinical features. ${ }^{12}$ We found that naloxone was administered to $5.6 \%$ of NFPs attended which is similar to the $6.2 \%$ found in a much larger study by Faul $e t a l^{25}$ Previous studies have shown an association between NFP and subsequent death from poisoning. ${ }^{22} 24$ In 2007, 189 people died of drug-related poisoning in Wales, the majority of whom $(70 \%$; 132/ 189) were male. ${ }^{15}$

This is the first study, to the best of our knowledge, in the UK to compare call centre data and data collected by attending ambulance crews for NFP and then to describe the epidemiology of NFP prehospital. Cantwell et $a l^{26}$ compared call centre data based on a triage algorithm with paramedic assessment in relation to falls and also found discrepancies across the two systems, although in this clinical area call data underestimated the true incidence by up to $13 \%$.

\section{Implications for policy, practice and further research}

This study brings into focus a number of issues that practitioners and policymakers need to address. It suggests that ambulance service data contain a wealth of useful data for studying the epidemiology of NFPs and in turn supporting the planning of future harm minimisation strategies, for measuring the success of interventions and for supporting ambulance crews in their role in relation to NFPs. However, current data systems do not readily support this. The more accurate and complete data recorded on scene by ambulance clinicians is gathered in WAST, as in many other UK ambulance services, on a paper record, and so is not readily collated, searched or interrogated. Much of the detail is recorded in the narrative section, rather than in tick box format, and so accessing it entails reading handwriting as well as interpreting and coding information which is likely to be non-standardised.

If PCRs cannot routinely be assessed and analysed as an alternative to call centre data, then there is a clear absence of robust data, placing risk management and injury prevention programmes at danger of being poorly informed and inadequately conceptualised. One way of rectifying this may be the introduction of electronic PCRs, but progress on this in Wales has been hampered by lack of funding, lack of central direction and a shortage of network capacity. An alternative option which has been recently approved in Wales is the introduction of a digital pen, for use by ambulance clinicians. This offers a novel method of capturing handwritten data, which can be recorded and analysed electronically. This shift to electronic PCRs is underway in other ambulance services and to be welcomed. However, the issues relating to coding and the accuracy of triage systems in call centre records identified in this study will require continued assessment and quality improvement. Once electronic capture is achieved, there is a further need to invest in information systems that link call and on scene information/patients who make multiple calls/and 
prehospital and ED data to improve our understanding of individuals help-seeking behaviour and outcomes.

The out-of-hours of presentation found in this study has resource implications for ambulance, ED, psychiatric services, primary care managers and unscheduled care providers. These services need to be organised, so that NFP patients who attend ED or who are not transported can receive signposting to appropriate services for assessment, thereby reducing the risk for future repetition and identifying their needs. Future research should include assessment of the delivery of interventions in the prehospital setting.

\section{CONCLUSIONS}

Ambulance staff are often the first point of contact for those who self-poison, and this contact offers an opportunity for intervention. This study highlights that current policy, service organisation and delivery is being based on unreliable call centre data. More accurate and complete data are recorded on scene by ambulance staff. Traditionally, it has been recorded on paper with the use of free text, and so has been impractical for routine use to support analysis. The benefits of reliable, routinely collected electronic information are likely to be many. They could influence national strategies and policies as well as provide information on the needs of individuals, the design of prehospital interventions and improve service planning for unscheduled care.

Contributors All of the authors contributed to the conception and design of the study. RO, GT and AP contributed to data collection. AP, GT and AJ contributed to data analysis. AJ, AP, and $\mathrm{CO}$ prepared the manuscript. All authors approved the publication of the study.

Funding National Institute for Social Care and Health Research (NISCHR)Swansea Trials Unit RFS-12.

Competing interests None declared.

Provenance and peer review Not commissioned; externally peer reviewed.

Data sharing statement No additional data are available.

Open Access This is an Open Access article distributed in accordance with the Creative Commons Attribution Non Commercial (CC BY-NC 4.0) license, which permits others to distribute, remix, adapt, build upon this work noncommercially, and license their derivative works on different terms, provided the original work is properly cited and the use is non-commercial. See: http:// creativecommons.org/licenses/by-nc/4.0/

\section{REFERENCES}

1. Owens D, Horrocks J, House A. Fatal and non-fatal repetition of self-harm systematic review. Br J Psychiatry 2002;181:193-9.

2. CAPIC. The burden of injury in Wales. Public Health Wales NHS TRUST, 2012

3. Meltzer H, Lader D, Corbin T, et al. Non-fatal suicidal behaviour among adults aged 16 to 74 in Great Britain. London: Stationery Office, 2002.

4. Bergen $\mathrm{H}$, Hawton $\mathrm{K}$, Waters $\mathrm{K}$, et al. Premature death after self-harm: a multicentre cohort study. Lancet 2012;380:1568-74.
5. NICE. Understanding NICE guidance: treatments for drug misuse. London: NICE, 2007.

6. Royal College of Psychiatrists. Better services for people who self-harm: quality standards for healthcare professionals. 2006. http://www.rcpsych.ac.uk/PDF/Self-Harm\%20Quality\%20Standards. pdf (accessed 12 August 2016).

7. Joint Royal Colleges Ambulance Liaison Committee. UK Ambulance Services Clinical Practice Guidelines 2013. 3rd edn. Class Publishing Ltd, London. 2013.

8. Dietze P, Jolley D, Cvetkovski S, et al. Characteristics of non-fatal opioid overdoses attended by ambulance services in Australia. Aust N Z J Public Health 2004;28:569-75.

9. Heyerdahl F, Hovda KE, Bjornaas MA, et al. Pre-hospital treatment of acute poisonings in Oslo. BMC Emerg Med 2008;8:15.

10. Degenhardt L, Hall W, Adelstein BA. Ambulance calls to suspected overdoses: New South Wales patterns July 1997 to June 1999. Aust N Z J Public Health 2001;25:447-50.

11. Bammer G, Ostini R, Sengoz A. Using ambulance service records to examine nonfatal heroin overdoses. Aust J Public Health 1995;19:316-17.

12. Gwini SM, Shaw D, Mohammad I, et al. 013 Factors associated with adverse clinical features in patients presenting with non-fatal self-poisoning. Emerg Med J 2011;28:e1.

13. Deakin CD, Sherwood DM, Smith A, et al. Does telephone triage of emergency (999) calls using advanced medical priority dispatch (AMPDS) with Department of Health (DH) call prioritisation effectively identify patients with an acute coronary syndrome? An audit of 42657 emergency calls to Hampshire Ambulance Service NHS Trust. Emerg Med J 2006;23:232-5.

14. Deakin CD, Alasaad M, King P, et al. Is ambulance telephone triage using advanced medical priority dispatch protocols able to identify patients with acute stroke correctly? Emerg Med $\mathrm{J}$ 2009;26:442-5.

15. Deaths related to drug poisoning in England and Wales, 2003-07. Health Stat $Q$ 2008;39:82-8. www.ons.gov.uk/.../subnational.../ deaths-related-to-drug-poisoning/2009. (accessed 12 August 2016).

16. Office for National Statistics. Deaths related to drug poisoning in England and Wales, Statistical Bulletin, 2009. 24th August 2010.

17. Welsh Government. Welsh Index of Multiple Deprivation 2011. 2011. http://gov.wales/docs/statistics/2011/111222wimd11techen.pdf. (accessed 12 August 2016).

18. The Countryside Agency. Rural and Urban Area Classification 2004 2004. http://webarchive.nationalarchives.gov.uk/20110215111010/ http:/defra.gov.uk/evidence/statistics/rural/documents/ruraldefn/Rural_Urban_Introductory_Guide.pdf. (accessed 12 August 2016).

19. von Elm E, Altman DG, Egger M, et al. The Strengthening the Reporting of Observational Studies in Epidemiology (STROBE) statement: guidelines for reporting observational studies. Prev Med 2007:45:247-51.

20. Prescott K, Stratton R, Freyer A, et al. Detailed analyses of self-poisoning episodes presenting to a large regional teaching hospital in the UK. Br J Clin Pharmacol 2009;68:260-8.

21. Indig D, Copeland J, Conigrave KM, et al. Characteristics and comorbidity of drug and alcohol-related emergency department presentations detected by nursing triage text. Addiction 2010;105:897-906.

22. Gunnell D, Bennewith O, Peters TJ, et al. The epidemiology and management of self-harm amongst adults in England. J Public Health (Oxf) 2005;27:67-73.

23. Hickey $\mathrm{L}$, Hawton $\mathrm{K}$, Fagg J, et al. Deliberate self-harm patients who leave the accident and emergency department without a psychiatric assessment: a neglected population at risk of suicide. J Psychosom Res 2001:50:87-93.

24. Kapur N, Cooper J, Hiroeh U, et al. Emergency department management and outcome for self-poisoning: a cohort study. Gen Hosp Psychiatry 2004;26:36-41.

25. Faul M, Dailey MW, Sugerman DE, et al. Disparity in naloxone administration by emergency medical service providers and the burden of drug overdose in US rural communities. Am J Public Health 2015;105:e26-32.

26. Cantwell K, Burgess S, Morgans A, et al. Temporal trends in falls cases seen by EMS in Melbourne: the effect of residence on time of day and day of week patterns. Injury 2016;47:266-71. 